\title{
Aplikasi Pengelolaan Pendapatan dan Pengeluaran Kas Pada Rafa Laundry Berbasis Web
}

\author{
Yeni Mardi ${ }^{1}$, Andi Saputra ${ }^{2}$, Sri Murni ${ }^{3}$, Weiskhy Steven Dharmawan ${ }^{4}$
}

\begin{tabular}{ll}
\hline \hline \multicolumn{2}{l}{ Info Artikel } \\
\hline & \\
Diterima & Juni 12, 2020 \\
Revisi & Juli 16, 2020 \\
Terbit & September 30, 2020 \\
& \\
\hline
\end{tabular}

Keywords:

Cash Income

Expenses

Waterfall Model

Laundry Application

\begin{abstract}
Rafa Laundry is a service business that offers cleaning clothes, carpets, dolls, bags and other textile materials. In every business process, Rafa Laundry still uses paper media in the form of books and notes, this is because Rafa Laundry has not implemented a computerized system. As a result of the computerized running system, the recording process is vulnerable to loss and damage, another weakness, namely processing data into information or reports that take a long time. This computerized system makes Rafa Laundry employees have to summarize daily transactions, income transactions and disbursement transactions, income transactions paid by customers are income for Rafa Laundry. Therefore, in this study to design and build a management application of income and cash outlays at Rafa Laundry, by applying the waterfall software development method.
\end{abstract}

\section{Identitas Penulis:}

Yeni Mardi ${ }^{1}$, Andi Saputra ${ }^{2}$, Sri Murni ${ }^{3}$, Weiskhy Steven Dharmawan ${ }^{4}$ Universitas Bina Sarana Informatika Program Studi Sistem Informasi Akuntansi Kampus Pontianak. Jalan Abdurrahman Saleh No.18 A Pontianak Email: yeniankar83@gmail.com¹, andisaputra001317@gmail.com², sri.six@bsi.ac.id ${ }^{3}$, weiskhy.wvn@bsi..ac.id ${ }^{4}$

\section{PENDAHULUAN}

Dewasa ini perkembangan sistem informasi semakin berkembang maju dan mendorong instansi swasta dan instansi pemerintah untuk menerapkan teknologi tersebut, dengan tujuan untuk mempermudah pekerjaan, dan membuat pekerjaan menjadi lebih efektif. Berkembangnya teknologi informasi dan sistem informasi di era sekarang membuat aspek-aspek kehidupan tidak dapat terhindarkan dari penggunaan internet meaupun perangkat computer.

Pemanfaatan media internet, dapat diwujudkan salah satunya dengan membuat sebuah sistem informasi berbasis website. Website adalah sebuah sistem yang dinamis dan interaktif dan aturan-aturan yang diimplementasikan pada sebuah web dinamis sehingga proses interaksi dapat berjalan dengan baik dan dapat diterima dan di akses oleh pengguna [1]. Salah satu perusahaan yang dapat menerapkan teknologi adalah pada bidang perdagangan.

Penggunaan internet selain untuk bersosial juga dapat digunakan sebagai sistem informasi, sistem informasi yang memanfaatkan internet atau berbasis website memudahkan penggunanya agar dapat mengakses dimanapun dan kapanpun, karena dengan berbasis website, maka basis data tersimpan di server hosting sehingga lebih mudah diakses. Sistem informasi saat ini sudah banyak menggunakan teknologi internet misalkan penjualan online, web profil, pelayanan jasa laundry. Jika sistem informasi berbasis website diterapkan pada pelayanan jasa laundry, maka dapat menguntungkan pemilik usaha, karena dapat melakukan monitoring dari jarak jauh tanpa harus datang ke tempat usaha. Proses pengolahan data menjadi informasi pendapatan dan pengeluaran pun mejadi lebih cepat.

Pada setiap proses bisnisnya Rafa Laundry masih menggunakan media kertas baik berupa buku maupun nota, hal tersebut karena Rafa Laundry belum menerapkan sistem yang terkomputer. Akibat dari masih 
belum terkomputernya sistem berjalan membuat proses pencatatan rentan akan hilang dan rusak, kelemahan lainnya yaitu proses pengolahan data menjadi sebuah informasi atau laporan membutuhkan waktu yang lama. Sistem yang belum terkomputer ini membuat karyawan Rafa Laundry harus merangkum transaksi setiap harinya, transaksi pendapatan dan transaksi kas keluar, transaksi pendapatan yang dibayarkan oleh pelanggan merupakan pendapatan bagi Rafa Laundry, sedangkan belanja keperluan administrasi dan bahan penolong serta gaji karyawan merupakan beban yang dikeluarkan melalui transaksi kas keluaran. Akibat dari proses pencatatan yang masih manual ini mengakibatkan sulitnya Rafa Laundry mengetahui laba bersih dari usaha yang dijalankan.

Berdasarkan dari uraian diatas, maka diperlukan sebuah sistem yang dapat mempermudah proses pencatatan transaksi dan pengolahan arus kas menjadi sebuah informasi terkomputerisasi.

\section{METODE PENGUMPULAN DATA}

1. Observasi

Penulis melakukan pengamatan langsung ke Rafa Laundry yang beralamatkan di jalan Mt.haroyono Kab.sintang. Observasi dilakukan mulai juni 2020 Ketika melakukan observasi peneliti mengamati prosedur sistem berjalan yang berkaitan dengan pelayanan jasa dan sistem pencatatan akuntansi seperti pendapatan dan pengeluaran kas, proses pencatatan masih menerapkan cara konvensional yaitu ditulis menggunakan buku rekapan harian dan belum menerapkan sistem terkomputerisasi.

2. Wawancara

Penulis melakukan tanya jawab kepada pemilik Rafa Laundry dan salah satu karyawan dibagian penerimaan pakaian. Wawancara dilakukan selama melakukan kunjungan di lokasi laundry. Penulis menanyakan hal-hal yang berkaitan dengan sistem berjalan kepada narasumber yaitu Ibu sumani selaku Pemilik usaha untuk mencari permasalahan yang dapat diperbaiki. Dari hasil wawancara dapat diperoleh beberapa permasalahan, permasalahan tersebut yaitu proses pencatatan arus kas yang masih konvensional dan rentan akan kesalahan.

3. Studi Pustaka

Penulis melakukan studi pustaka dengan mencari referensi-referensi jurnal ilmiah dan buku-buku yang berkaitan dengan permasalahan yang dibahas.

\subsection{Metode Pengembangan Perangkat Lunak}

Metode pengembangan perangkat lunak pada penilitian Tugas Akhir, peneliti menggunakan metode System Development Lyfe Cycle (SDLC) model air terjun (Waterfall). Model air terjun (waterfall) sering juga disebut model sekuensial linier (sequential linear) atau alur hidup klasik (classic life cycle). Model air terjun menyediakan pendekatan alur hidup perangkat lunak secara sekuensial atau terurut dimulai dari Analisis, Desain, Pengkodean, Pengujian dan Pemeliharaan [2]. Penjelasan dari masing-masing alur model waterfall adalah sebagai berikut.

1. Analisis

Pada tahapan ini dilakukan pengumpulan kebutuhan data dengan cara wawancara dan observasi. Penulis memberikan pertanyaan terbuka mengenai permasalahan yang didapat selama pengamatan secara langsung.

2. Desain

Pada tahap ini dilakukan pemodelan struktur data dan hubungan antar data menggunakan entity relationship diagram (ERD) diagram ini dibuat menggunakan aplikasi online situs erdplus.com dan logical record structured (LRS) sesuai dengan kebutuhan yang ada, yang dibuat menggunakan fitur schema designer pada aplikasi SQLyog.

3. Pengkodean

Pada tahap ini penulis mengaplikasikan desain yang telah dibuat ke dalam program perangkat lunak. Aplikasi yang dirancang menggunakan database MySQL, XAMPP sebagai local server, SQLyog sebagai DBMS (Database Management System) pembuatan database, bahasa pemograman yang digunakan PHP (Hypertext Preprocessor), javascript dan jQuery, kerangka kerja menggunakan framework CodeIgniter version 3.1.10 agar sistem yang dibuat berbasis object [3].

4. Pengujian

Pada tahap ini peneliti melakukan pengujian terhadap sistem informasi berbasis website yang telah dibuat menggunakan metode Black-Box Testing. Tahap pengujian berfokus pada spesifikasi fungsional dari 
perangkat lunak, penguji dapat mendefinisikan kumpulan kondisi masukan dan melakukan pengujian pada spesifikasi fungsional program.

5. Pemeliharaan

Tahap pemeliharaan dapat mengulangi proses pengembangan mulai dari tahap analisis spesifikasi untuk perubahan perangkat lunak baru, karena tidak menutup kemungkinan sebuah perangkat lunak mengalami perubahan, kesalahan yang muncul dan tidak terdeteksi saat pengujian. Mengantisipasi perkembangan maupun perubahan sistem bersangkutan terkait dengan hardware dan software yang akan digunakan.

\section{HASIL}

Hasil penelitian dimulai dengan memaparkantahapan hasil analisa pada sistem berjalan. Dipaparkan dalam bentuk apa adanya dan pada tahapan tertentu diolah untuk memudahkan peneliti dalam menyajikan hasil penelitian sehingga pembaca dapat dengan mudah memahami pembahasan. Tahapan penelitian dimulai dengan memaparkan tinjuan kasus secara rinci, pencatatan transaksi pendapatan dan pengeluaran pada kas dan kemudian pengimplementasian sistem yang sudah di rancang.

\subsection{Tinjauan Kasus}

Tinjauan kasus akan memaparkan akan dijelaskan dengan beberapa subbab, yaitu proses bisnis sistem berjalan, activity diagram, dokumen masukan, dokumen keluarn, permasalahan pokok dan pemecahan masalah.

\subsection{Proses Sistem Berjalan}

Prosedur sistem berjalan merupakan tahapan-tahapan kegiatan yang dilakukan dalam melakukan aktifitas dan rutinitas. Adapun prosedur sistem berjalan yang diterapkan oleh Rafa Laundry adalah sebagai berikut.

1. Proses Transaksi Pendapatan

Pelanggan dapat memasukan pakaian dengan cara datang langsung ke toko Rafa Laundry, kemudian pakaian akan ditimbang lalu pelanggan akan ditanyai tentang paket mana yang diinginkan setelah itu dibuatkan nota transaksi pembayaran. Pada nota tersebut tercatat jumlah pembayaran yang diberikan oleh pelanggan, pembayaran dapat dilakukan dengan cara pembayaran lunas diakhir, lunas diawal, atau pembayaran sebagian. Pakaian yang sudah selesai berdasarkan tanggal yang tertera pada nota, dapat diambil oleh pelanggan dengan syarat membawa nota pembayaran. Berdasarkan nota tersebut bagian keuangan akan mencatat sebagai pendapatan dan membuat laporan ke Pemilik usaha.

2. Proses Transaksi Pengeluaran

Sistem pelayanan laundry tentunya juga membutuhkan pengeluaran dana, baik dana untuk kebutuhan operasional, administrasi atau beban lainnya. Dana yang dikeluarkan akan dicatat dan disimpan bukti kwitansinya sebagai bahan pelaporan dana keluar oleh bagian keuangan untuk diserahkan ke pemilik usaha.

\subsection{Use Case Digram}

Diagram Use Case digunakan untuk memudahkan pembaca dalam memahami fungsional sistem yang dibangun. Diagram Use Case yang dibuat pada tahap ini berdasarkan yang analisa kebutuhan yang sudah dipaparkan sebelumnya. Berikut Use Case diagram yang telah dibuat pada sistem pendapatan dan pengeluaran kas pada Rafa Laundry. 


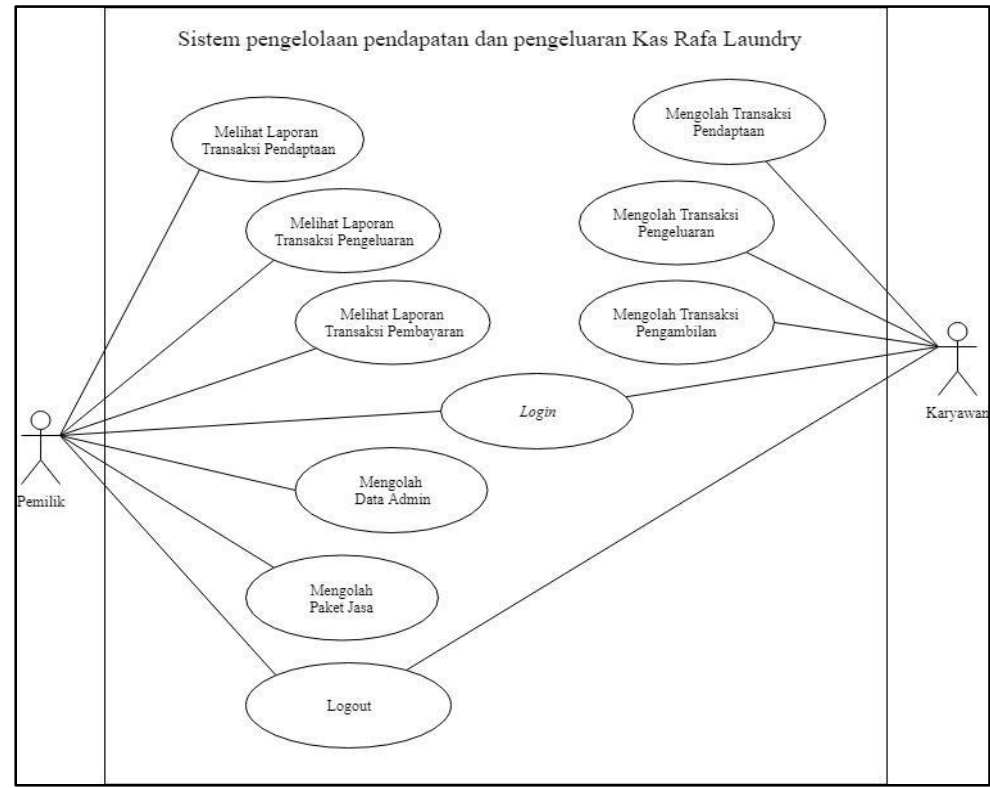

Sumber: Hasil Penelitian (2020)

\section{Gambar 1. Use Case Diagram}

\subsection{Activity Diagram}

Activity diagram dapat menggambarkan workflow (aliran kerja) atau aktivitas dari sebuah sistem atau proses bisnis. Diagram activity pada perancangan sistem ini dibagi menjadi activity login, activity transaksi pesanan, activity transaksi penerimaan, activity transaksi pengambilan, dan activity cetak laporan. Berikut diagram acitivity berdasarkan sistem usulan yang dibuat guna menerangkan tentang aktifitas yang dilakukan.

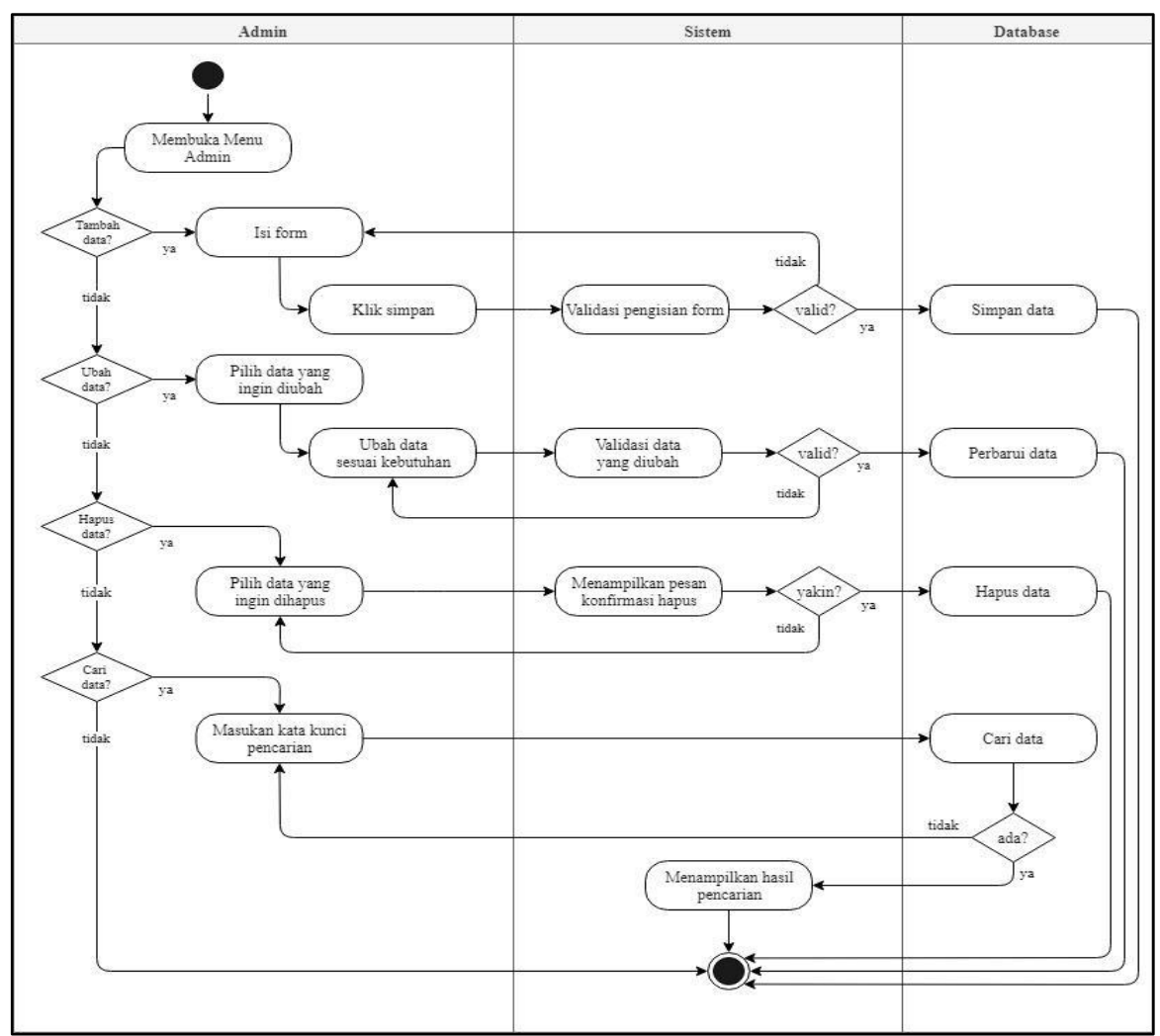

Sumber: Hasil Penelitian (2020)

Gambar 2. Activity Diagram Halaman Mengelola Admin 


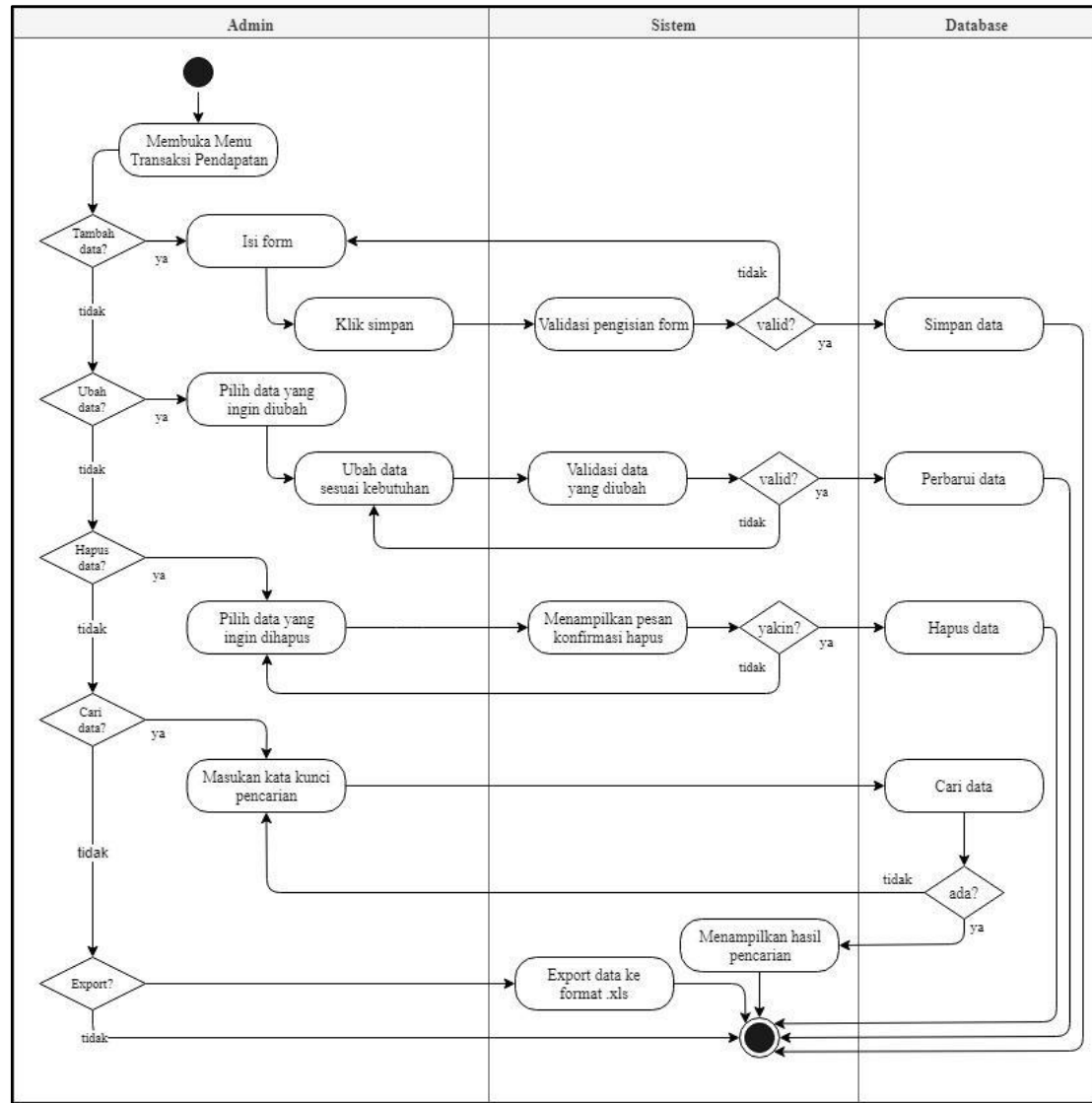

Sumber: Hasil Penelitian (2020)

Gambar 3. Activity Diagram Halaman Mengelola Transaksi Pendapatan 


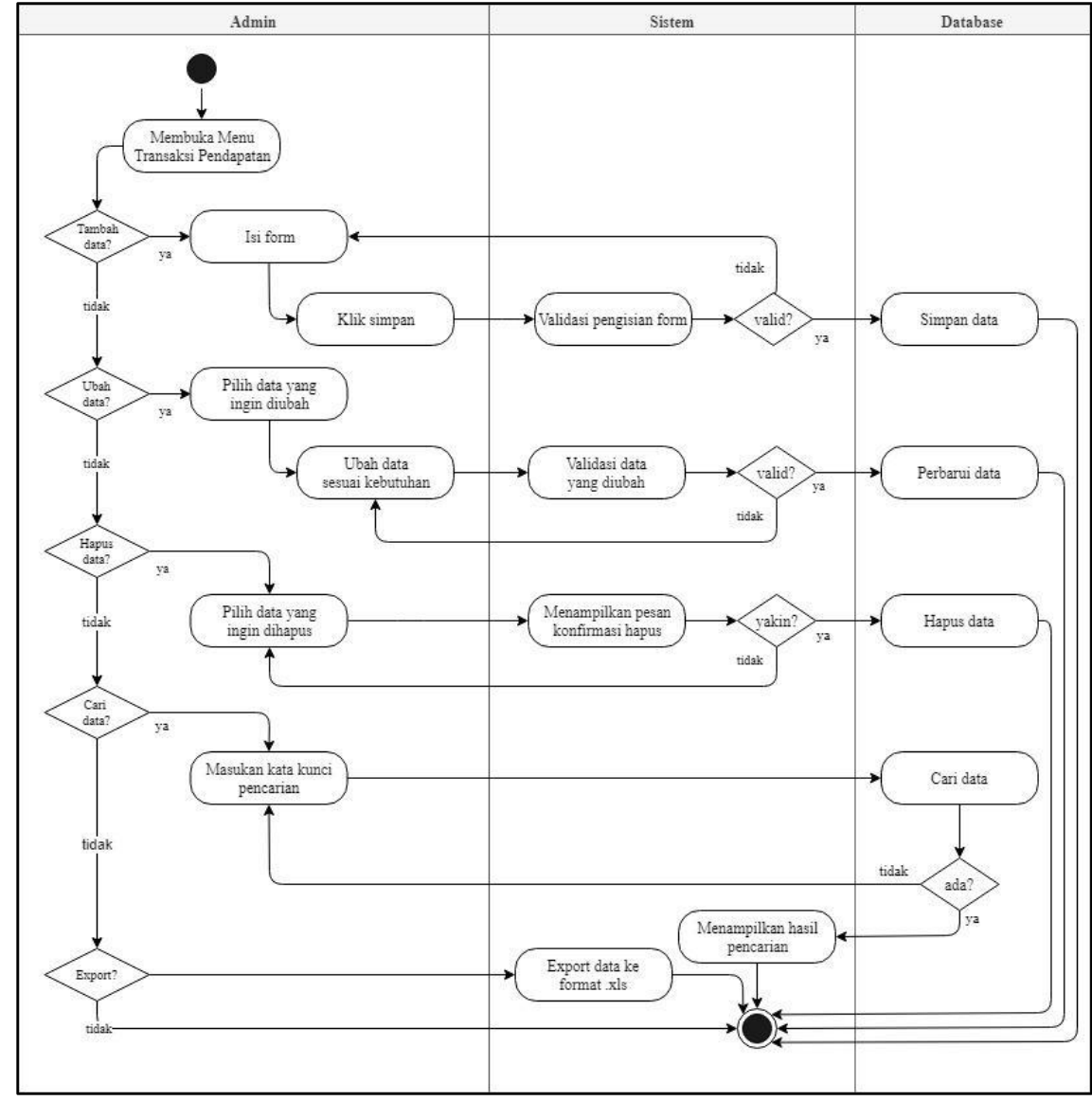

Sumber: Hasil Penelitian (2020)

Gambar 4. Activity Diagram Halaman Mengelola Transaksi Pengeluaran

\subsection{User Interface}

User interface akan berisi mengenai penggambaran interface dari rancangan program yang dibuat pada penulisan ini sesuai dengan hasil penelitian dan analisa kebutuhan yang telah dijelaskan sebelumnya.

1. User Interface Login

Login diperlukan untuk masuk kedalam sistem, untuk masuk ke dalam sistem admin harus mengisi email dan password yang telah terdaftar sebelumnya, jika email dan password yang dimasukan benar atau valid, maka akan dialihkan ke halaman beranda sistem, namun jika email dan password yang dimasukan salah maka sistem akan menampilkan pesan kesalahan. Berikut user interface halaman login.

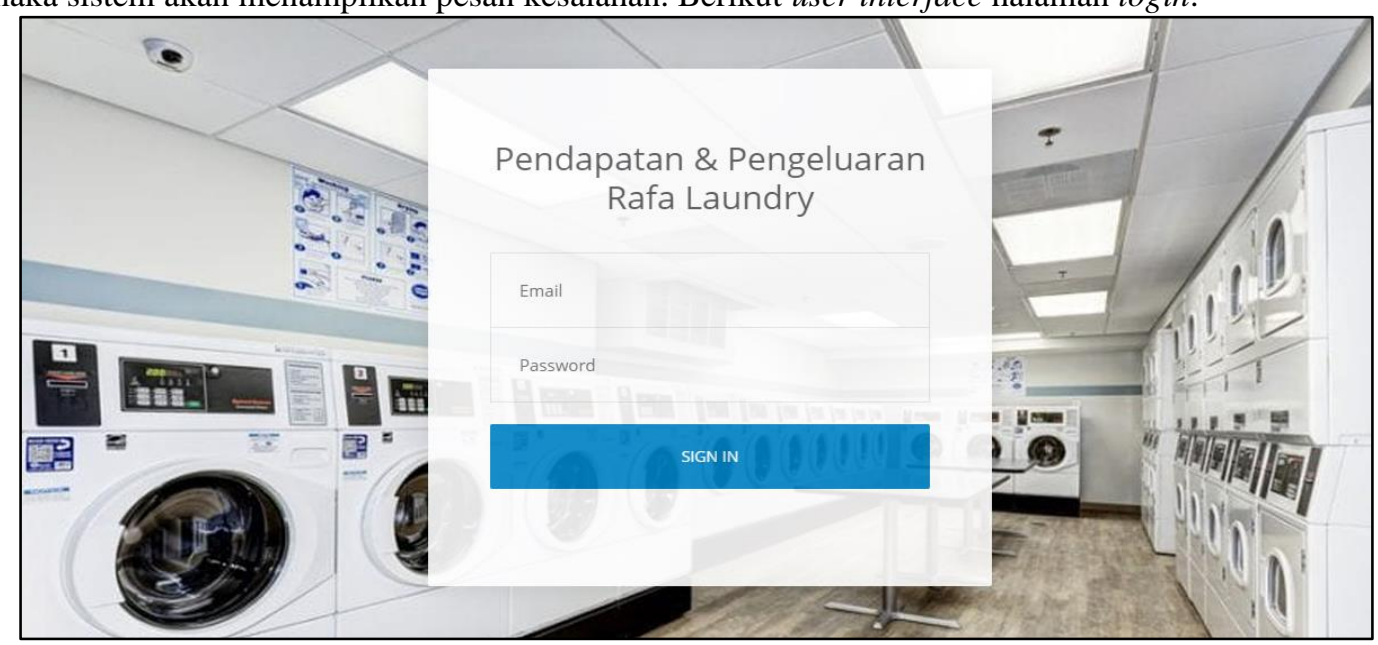

Sumber: Hasil Penelitian (2020)

Gambar 5. User Interface Login 


\section{User Interface Dashboard}

Halaman dashboard menampilkan beberapa informasi singkat yang berkaitan dengan pendapatan dan pengeluaran kas pada Rafa Laundry. Berikut user interface halaman dashboard.

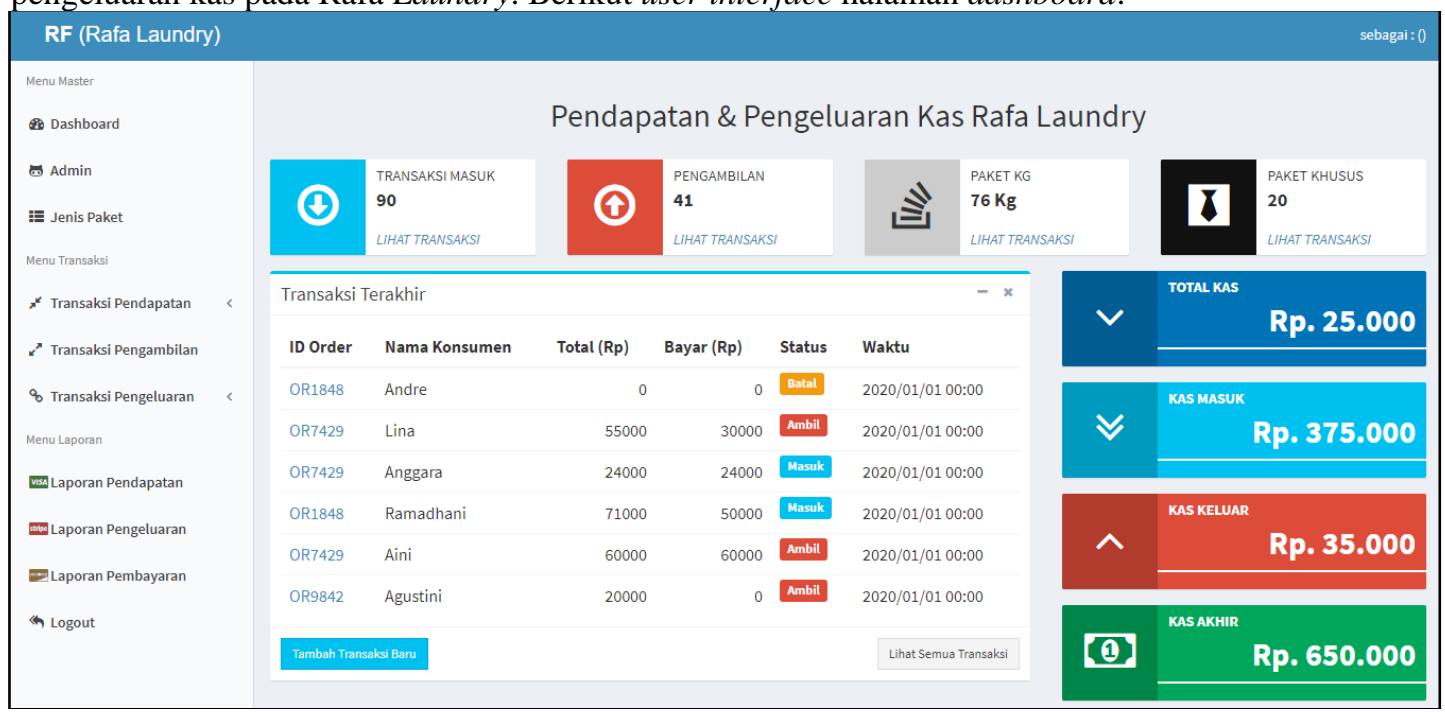

Sumber: Hasil Penelitian (2020)

Gambar 6. User Interface Dashboard

\section{.3. User Interface Mengelola Admin}

Pengelolaan admin pada sistem yang dibuat pada tugas akhir ini, yaitu dapat melakukan beberapa fungsi pengelolaan data seperti, tambah data, perbarui data, hapus data, melihat detail data, dan pencarian. Berikut user interface halaman admin.

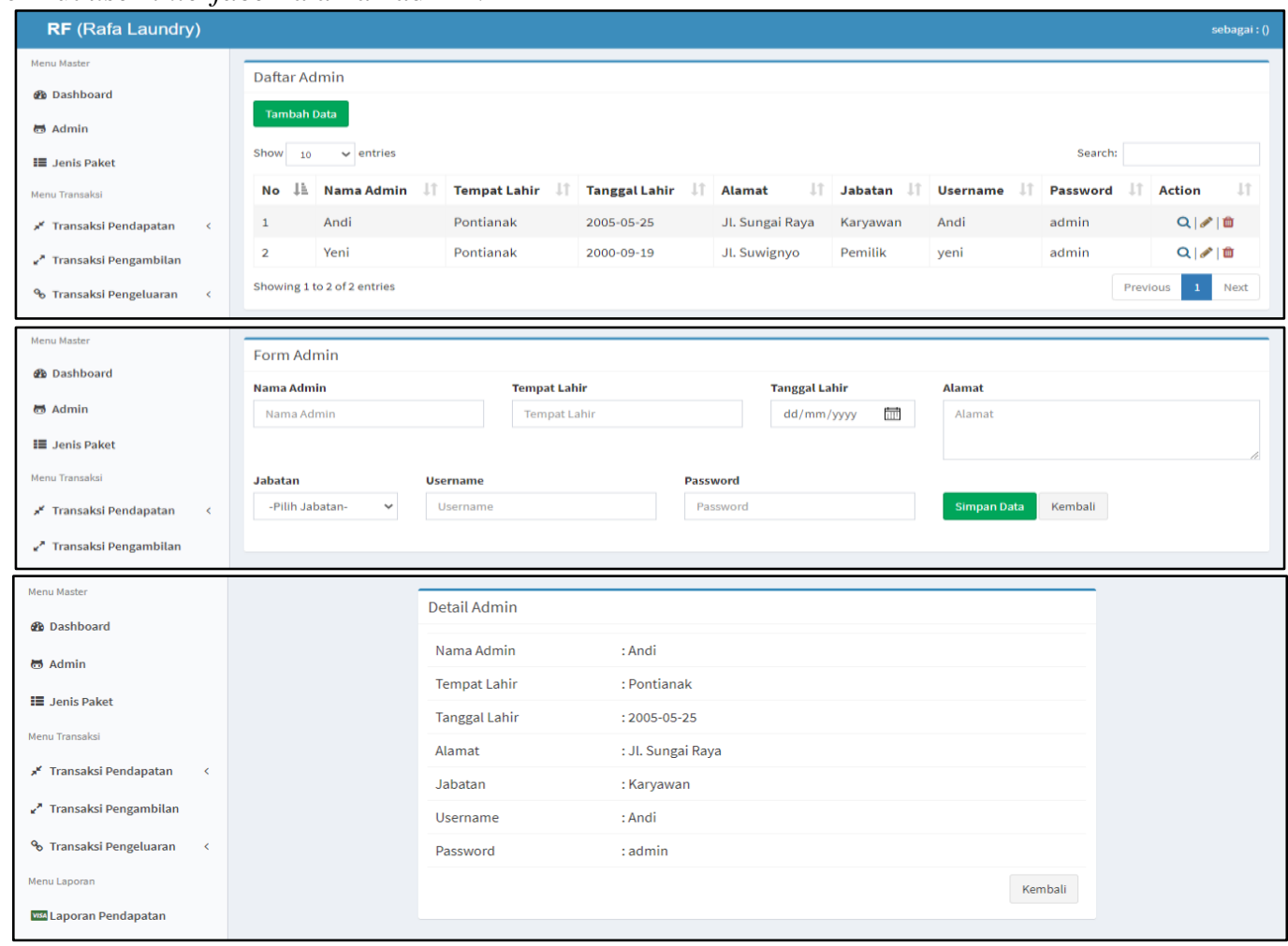

Sumber: Hasil Penelitian (2020)

Gambar 7. User Interface Mengelola Admin 
4. User Interface Mengelola Transaksi Pendapatan

Pengelolaan transaksi pendapatan pada sistem yang dibuat pada tugas akhir ini, yaitu dapat melakukan beberapa fungsi pengelolaan data seperti, tambah data, perbarui data, hapus data, melihat detail data, dan pencarian serta dapat melakukan export data. Berikut user interface halaman transaksi pendapatan.

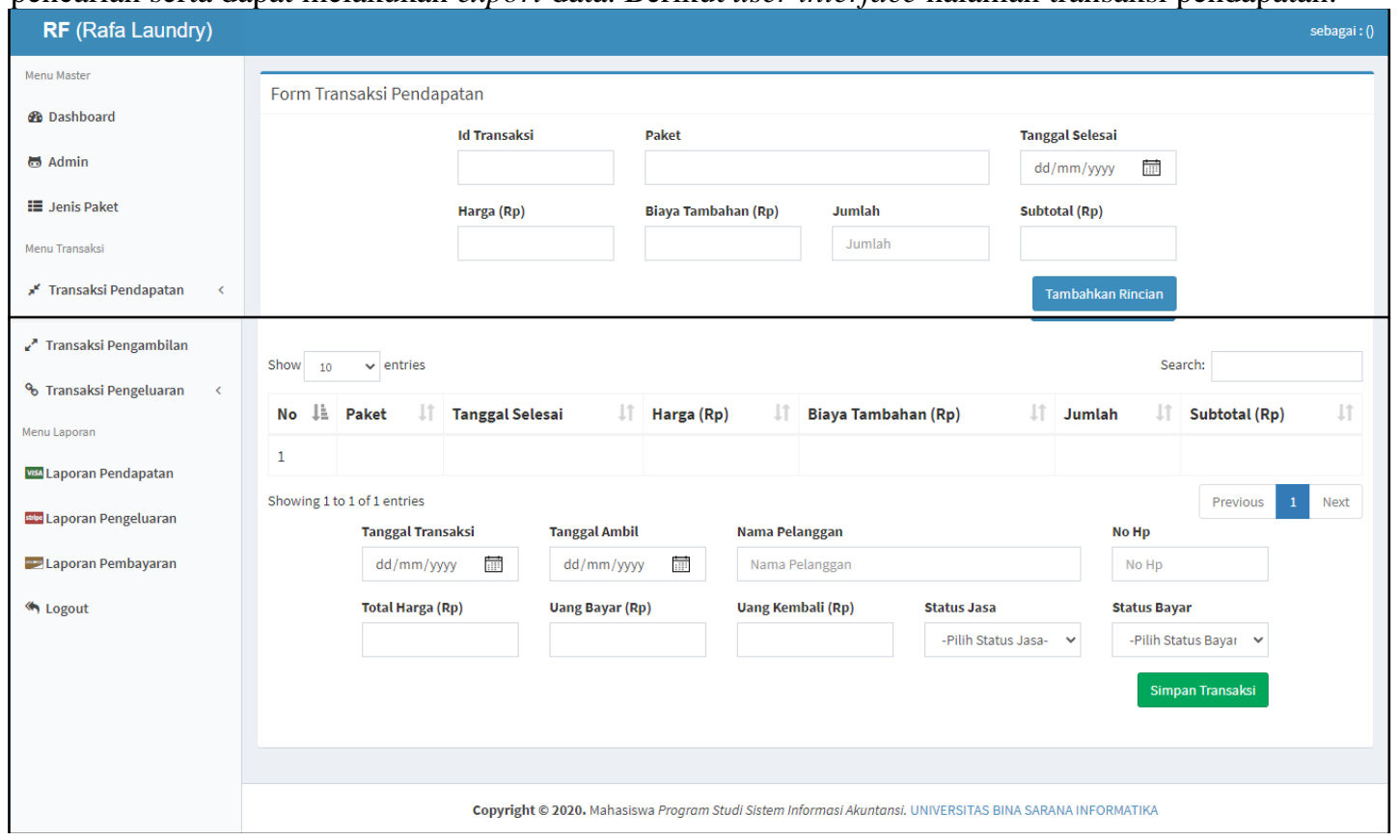

Gambar 8. User Interface Mengelola Transaksi Pendapatan

5. User Interface Mengelola Transaksi Pengeluaran

Pengelolaan transaksi pengeluaran pada sistem yang dibuat pada tugas akhir ini, yaitu dapat melakukan beberapa fungsi pengelolaan data seperti, tambah data, perbarui data, hapus data, melihat detail data, dan pencarian serta dapat melakukan export data. Berikut user interface halaman transaksi pengeluaran.

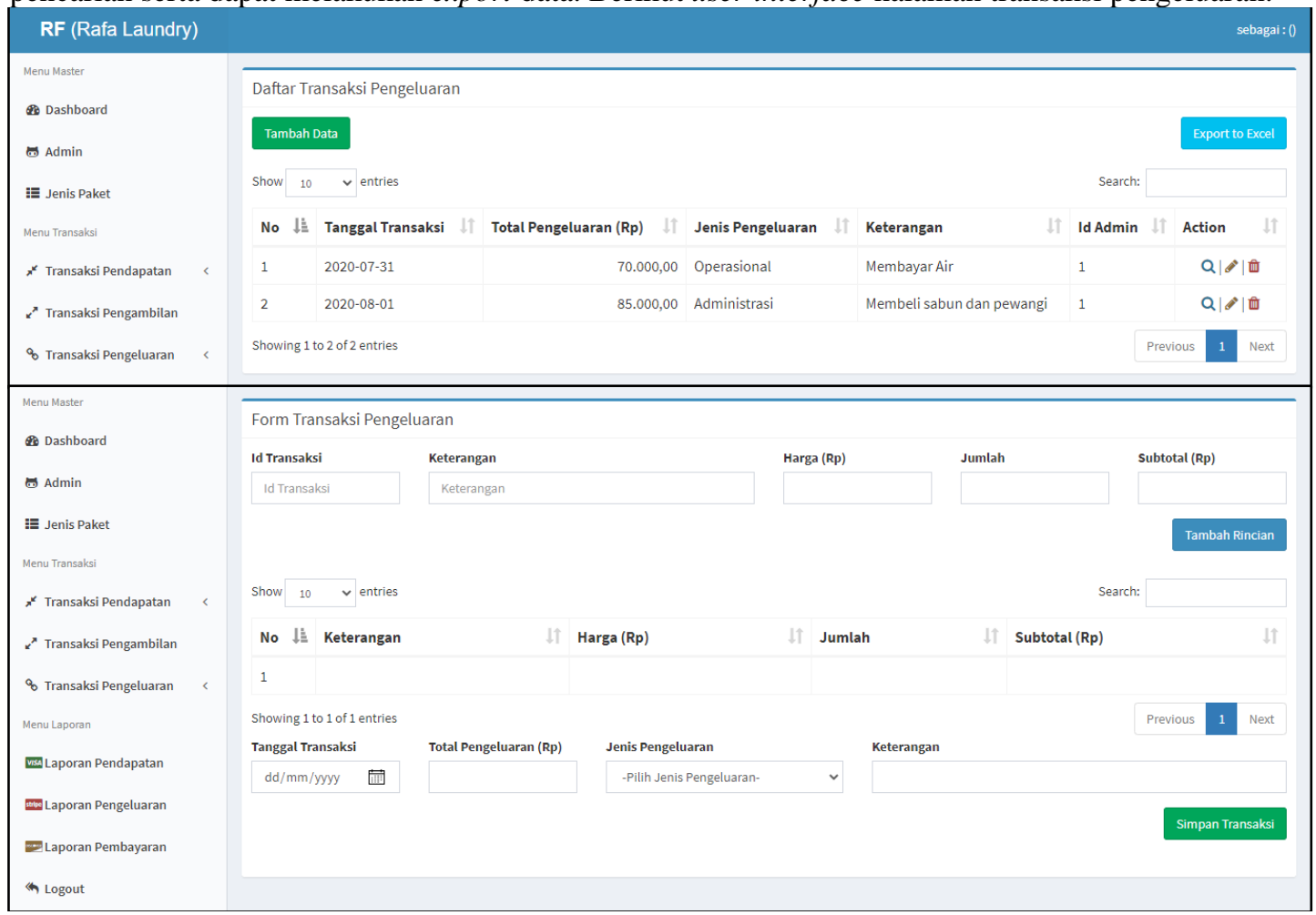

Sumber: Hasil Penelitian (2020)

Gambar 9. User Interface Mengelola Transaksi Pengeluaran 


\section{KESIMPULAN}

Kesimpulan yang dapat diambil dari penerapan aplikasi pendapatan dan pengeluaran kas pada Rafa Laundry adalah memberikan kontribusi bagi pengguna dalam mendapatkan informasi lebih cepat dibandingkan secara konvensional dengan adanya sistem yang sudah dirancang, serta menghasilkan laporan yang lebih akurat dalam waktu yang singkat dibandingkan dengan cara biasa dan penggunaan sistem informasi dapat memudahkan proses pengelolaan transaksi pendapatan dan transaksi pengeluaran kas yang terjadi karena sistem berjalan yang akan terkomputer. Penerapan sistem informasi maka data dokumentasi menjadi lebih aman, serta memudahkan penggunanya mudah ketika membuat laporan.

\section{UCAPAN TERIMA KASIH}

Terima kasih kami ucapkan kepada seluruh pihak terkait atas terlaksananya penelitian ini, terutama kepada Allah swt, serta kepada pihak penerbit yang telah berkenan untuk menerbitkan paper ini.

\section{REFERENSI}

[1] J. G. Moreno-Torres, T. Raeder, R. Alaiz-Rodríguez, N. V. Chawla, and F. Herrera, “A unifying view on dataset shift in classification," Pattern Recognit., vol. 45, no. 1, pp. 521-530, 2012.

[2] W. S. Dharmawan, D. Purwaningtias, and D. Risdiansyah, "Penerapan Metode SDLC Waterfall Dalam Perancangan Sistem Informasi Administrasi Keuangan Berbasis Desktop,” J. Khatulistiwa Inform., vol. VI, no. 2, 2018.

[3] M. Shalahuddin, R. A. . (2016). M. Shalahuddin Rosa A. S (Revisi). Bandung: Informatika Bandung. 